\title{
A Simple Model of Foreign Brand Penetration under Monopolistic Competition
}

Toru Kikuchi

\section{EERI Research Paper Series No 14/2009}

ISSN: 2031-4892

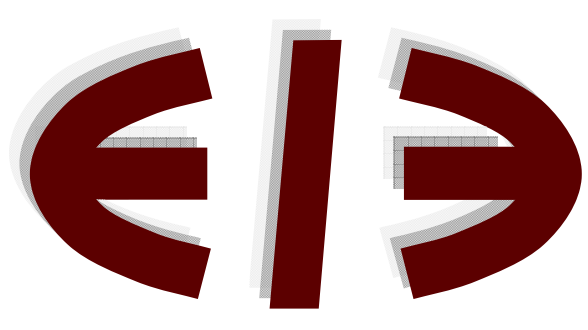

EERI

Economics and Econometrics Research Institute Avenue de Beaulieu

1160 Brussels

Belgium

Tel: +3222993523

Fax: +322 2993523

www.eeri.eu 


\title{
A Simple Model of Foreign Brand Penetration under Monopolistic Competition
}

\author{
Toru Kikuchi*
}

July 7, 2009

\begin{abstract}
The main purpose of this study is to illustrate, with a simple monopolistic competition trade model, how trade liberalization (i.e., a decline in trade costs) can affect domestic entrepreneurs' decisions between domestic brands and foreign brands, and thus the degree of foreign brand penetration. It is shown that, as trade costs decrease, more entrepreneurs choose to provide foreign brands. However, the impact of trade liberalization (in terms of changes in profit levels) becomes smaller as more entrepreneurs switch to foreign brands.
\end{abstract}

${ }^{*}$ Graduate School of Economics, Kobe University, Rokkodai 2-1, Kobe 657-8501, Japan. Email: kikuchi@econ.kobe-u.ac.jp 
Keywords: Foreign brand penetration, trade liberalization, monopolistic competition

JEL Classification: F12 


\section{Introduction}

The proliferation of trade liberalization through both economic integration (e.g., the European Union) and trade agreements (e.g., the WTO) has made foreign brand penetration a significant issue in many countries. ${ }^{1}$ Accordingly, many studies have examined the impact of trade liberalization on foreign brand penetration, typically using trade models of monopolistic competition, which assume the existence of differentiated brands. The simplest models of monopolistic competition presume that, due to trade liberalization, every foreign firm increases its exports. This implies that the number of imported brands remains unchanged by trade liberalization itself. ${ }^{2}$

The past literature ignores one important aspect of real life: the fact that foreign producers and domestic sellers are often different entities. For example, cars are most often sold abroad by dealers who are nationals of the country where the cars are sold. In the Japanese apparel industry, apparel companies (including trading companies such as C. Itoh and Mitsui) have concentrated on licensing high-quality imported (European and US) brands. In particular, there was a large increase in the number of imported brands during the 1980s and 1990s. Related to this, Porter, Takeuchi and Sakakibara

\footnotetext{
${ }^{1}$ Another important aspect of foreign penetration is foreign direct investment. Ono (1990) and Richardson (1998) use oligopoly models to deal with this point.

${ }^{2}$ See, for example, Helpman and Krugman (1985) and Helpman (1990).
} 
(2000) state: ${ }^{3}$

The more agreements the Japanese rivals signed, frequently with licensors based in the same countries, especially Italy, the more similar they became. As a flood of imported brands hit the Japanese market, their appeal waned.

These examples seem to suggest that the focus on increased foreign brand penetration should be accompanied by a focus on domestic importers' behaviors. $^{4}$

The main purpose of this study is to illustrate, with a simple trade model of monopolistic competition, how trade liberalization (i.e., a decline in trade costs) can affect domestic entrepreneurs' decision of whether to provide domestic brands or foreign brands and the degree of foreign brand penetration. Following Matsuyama (1995), I assume that there are two groups of differentiated products, domestic brands and imported brands, each of which must be set up and managed by entrepreneurs. Matsuyama assumed a closed economy and paid scant attention to the role of trade liberalization. In contrast,

\footnotetext{
${ }^{3}$ Porter, Takeuchi and Sakakibara (2000, p. 88).

${ }^{4}$ One of the important modes of foreign brand penetration is "brand name collaboration" in which domestic sellers use foreign competitors' brand names to increase demand. In their seminal paper, Marjit, Beladi and Kabiraj (2007) analyze this aspect. They find that such an agreement is likely to occur between the firms which are not "too apart" in terms of their initial brand reputation.
} 
in this study I focus on the case of trade and examine the interaction between trade liberalization and entrepreneurs' decision making.

The structure of the paper is as follows: In the next section I present a basic trade model of monopolistic competition. In Section 3, the impact of trade liberalization is considered. Concluding remarks are presented in Section 4.

\section{The Model}

Suppose there are two countries, Home and Foreign. The discussion that concentrates on what happens in the Home market. Each consumer in Home is endowed with the amount $E$ of income to be spent on differentiated brands. Suppose there are two groups of differentiated products: domestically produced brands with an aggregator denoted by $h$, and imported brands with an aggregator denoted by $f$. The sub-utility function and the corresponding price index for differentiated brands are:

$$
\begin{gathered}
C=\left[\alpha_{h} C_{h}^{\frac{\varepsilon-1}{\varepsilon}}+\alpha_{f} C_{f}^{\frac{\varepsilon-1}{\varepsilon}}\right]^{\frac{\varepsilon}{\varepsilon-1}} \\
P=\left[\alpha_{h}^{\varepsilon} P_{h}^{1-\varepsilon}+\alpha_{f}^{\varepsilon} P_{f}^{1-\varepsilon}\right]^{\frac{1}{1-\varepsilon}}
\end{gathered}
$$

where $\varepsilon>1$ is the elasticity of substitution between groups, $C_{i}$ and $P_{i}$ are the quantity and price indices for group $i(i=h, f)$. Note that $\alpha_{f} / \alpha_{h}$ mea- 
sures the relative preference towards imported brands. ${ }^{5}$ Total expenditure on differentiated brands is defined as

$$
E \equiv P C
$$

In what follows, assume that $E$ is exogeneously given.

The quantity index for group $i$ takes the Dixit-Stiglitz (1977) form

$$
C_{i}=\left[\int_{0}^{n_{i}} c_{i}(j)^{\frac{\sigma-1}{\sigma}} d j\right]^{\frac{\sigma}{\sigma-1}}, i=h, f
$$

where $\sigma>1$ is the elasticity of substitution between brands within a group, $c_{i}(j)$ is the amount of consumption of brand $j$ in group $i$, and $\left[0, n_{i}\right]$ represents the range of brands available in the marketplace. The corresponding price index for group $i$ is:

$$
P_{i}=\left[\int_{0}^{n_{i}} p_{i}(j)^{1-\sigma} d j\right]^{\frac{1}{1-\sigma}}, i=h, f
$$

where $p_{i}(j)$ is the price of brand $j$ in group $i$. The demand function for each brand $j$ in group $i$ satisfies

$$
\begin{aligned}
c_{i}(j) & =\left[\frac{p_{i}(j)}{P_{i}}\right]^{-\sigma} C_{i}, i=h, f, \\
\frac{C_{h}}{C_{f}} & =\left(\frac{\alpha_{h}}{\alpha_{f}}\right)^{\varepsilon}\left(\frac{P_{h}}{P_{f}}\right)^{-\varepsilon} .
\end{aligned}
$$

In each group, differentiated brands are produced by monopolistically competitive firms. One of the central assumptions is that each firm needs to

\footnotetext{
${ }^{5}$ A similar setting is introduced in Venables (1987).
} 
be set up and managed by an entrepreneur. There are $N$ entrepreneurs in Home. Each entrepreneur has to decide what type of brand to provide. They are two options: (1) to set up a domestic firm by hiring Home labor at wage rate $w_{h}$ and provide a domestic brand; or (2) to set up an intermediary and import a Foreign brand for Home consumers. ${ }^{6}$ In the second case, Foreign brands are assumed to be produced by hiring Foreign labor at wage rate $w_{f}$. To simplify the analysis, we assume that wage rates in both countries are exogenously given.

In order to simplify the analysis, to produce one unit of any brand, one unit of labor is required. Given a Dixit-Stiglitz specification with constant elasticity $\sigma$ and a labor wage rate $w_{i}$, each firm in group $i$ sets its mill price $\rho_{i}$ as

$$
\rho_{i}=\frac{\sigma w_{i}}{\sigma-1}, i=h, f
$$

Further assume that cross-border shipments of Foreign brands incurtrade costs via the "iceberg" effect: for every $t(t>1)$ units shipped, only one unit

\footnotetext{
${ }^{6}$ To simplify the argument, I assume that Home entrepreneurs can decide whether to import Foreign brands by themselves. It is more natural, however, to assume that such a deal needs agreement between Home entrepreneurs and Foreign producers. Marjit, Beladi and Kabiraj (2007) examine the latter case under a Cournot-Nash framework. It is important to extend their analysis to the case of a monopolistically competitive market structure.
} 
arrives. Thus, the price of an imported brand for Home consumers will be

$$
p_{f}=t \rho_{f}
$$

Now we can obtain the profit level for the firm in group $i$ :

$$
\pi_{i}=\frac{1}{n_{i} \sigma} P_{i} C_{i}, i=h, f
$$

The relative profit is

$$
\begin{gathered}
\frac{\pi_{f}}{\pi_{h}}=\frac{n_{h}}{n_{f}}\left(\frac{P_{f}}{P_{h}}\right)\left(\frac{C_{f}}{C_{h}}\right)=\frac{n_{h}}{n_{f}}\left(\frac{\alpha_{f}}{\alpha_{h}}\right)^{\varepsilon}\left(\frac{P_{f}}{P_{h}}\right)^{1-\varepsilon} \\
=\left(\frac{\alpha_{f}}{\alpha_{h}}\right)^{\varepsilon}\left(\frac{n_{f}}{n_{h}}\right)^{\frac{\varepsilon-\sigma}{\sigma-1}}\left(\frac{w_{h}}{w_{f} t}\right)^{\varepsilon-1} .
\end{gathered}
$$

Assume $\sigma>\varepsilon$ (i.e., substitutability within a group is greater than that between groups). The ratio of profit is thus inversely proportional to the ratio of the number of brands. ${ }^{7}$

Suppose that it takes time for entrepreneurs to move from one group to the next. This means that, in the short run, profits are not equalized. In the long run, the number of brands is determined by the movement of entrepreneurs such that all firms obtain equal profits (i.e., $\pi_{h}=\pi_{f}$ ).

Figure 1 shows the determination of the relative number of brands in the long run. The horizontal axis shows the relative number of brands $\left(n_{f} / n_{h}\right)$, while the vertical axis shows the relative profit level $\left(\pi_{h} / \pi_{f}\right)$. Given that

\footnotetext{
${ }^{7}$ See Matsuyama (1995, p. 714) on this point
} 
$\sigma>\varepsilon,(10)$ is shown as a downward-sloping curve. If the initial point is $I$, then the entrepreneurs will move from group $h$ to group $f$. In the long run, the equilibrium is obtained as the intersection of this curve and the $\pi_{h}=\pi_{f}$ line, point $E$. The long-run relative number of imported brands (measured in terms of the number of brands) is

$$
\frac{\tilde{n}_{f}}{\tilde{n}_{h}}=\left[\left(\frac{\alpha_{f}}{\alpha_{h}}\right)^{\varepsilon}\left(\frac{w_{h}}{w_{f} t}\right)^{\varepsilon-1}\right]^{\frac{\sigma-1}{\sigma-\varepsilon}},
$$

where "tilde" indicates the long-run equilibrium value.

Proposition 1: In the long run, the relative number of imported brands $\left(n_{f} / n_{h}\right)$ is positively related to their relative attractiveness $\left(\alpha_{f} / \alpha_{h}\right)$ and negatively related to its relative costs (inclusive of trade costs $t$ ).

This implies that the low rate of foreign brand penetration results from both strong preferences in favor of domestic brands and the existence of trade costs.

\section{Trade Liberalization}

Suppose that there is a reduction in trade costs for imported brands: a decrease in $t$. From (4), (7) and (8),

$$
P_{h}=\left(n_{h}\right)^{\frac{1}{1-\sigma}} \rho_{h},
$$




$$
P_{f}=\left(n_{f}\right)^{\frac{1}{1-\sigma}} t \rho_{f}
$$

Thus, the relative price level becomes:

$$
\frac{P_{h}}{P_{f}}=\left(\frac{n_{h}}{n_{f}}\right)^{\frac{1}{1-\sigma}}\left(\frac{w_{h}}{t w_{f}}\right) .
$$

A reduction in $t$ increases the relative price level, $P_{h} / P_{f}$, and

$$
\left(\frac{\hat{P}_{h}}{P_{f}}\right)=-\frac{1}{\sigma-1}\left(\frac{\hat{n_{h}}}{n_{f}}\right)+\left(\frac{\hat{w_{h}}}{t w_{f}}\right),
$$

where "hat" indicates a percentage change.

In order to examine the impact of trade liberalization, it is useful to check the profit level of each firm $\left(\pi_{h}\right.$ and $\left.\pi_{f}\right)$. Rewriting (9), the profit levels for firms are

$$
\begin{aligned}
& \pi_{h}=\frac{1}{n_{h} \sigma} P_{h} C_{h}=\frac{1}{n_{h} \sigma}\left[1-\mu_{f}\left(\frac{P_{h}}{P_{f}}\right)\right] E, \\
& \pi_{f}=\frac{1}{n_{f} \sigma} P_{f} C_{f}=\frac{1}{n_{f} \sigma} \mu_{f}\left(\frac{P_{h}}{P_{f}}\right) E,
\end{aligned}
$$

where $\mu_{f}\left(P_{h} / P_{f}\right)$ is the relative expenditure share for group- $f$ brands:

$$
\begin{gathered}
\mu_{f}\left(\frac{P_{h}}{P_{f}}\right) \equiv \frac{\alpha_{f}^{\varepsilon} P_{f}^{1-\varepsilon}}{\alpha_{h}^{\varepsilon} P_{h}^{1-\varepsilon}+\alpha_{f}^{\varepsilon} P_{f}^{1-\varepsilon}}=\frac{\alpha_{f}^{\varepsilon}}{\alpha_{h}^{\varepsilon}\left(P_{h} / P_{f}\right)^{1-\varepsilon}+\alpha_{f}^{\varepsilon}}, \\
\mu_{f}^{\prime}\left(\frac{P_{h}}{P_{f}}\right)=\frac{(\varepsilon-1) \alpha_{h}^{\varepsilon} \alpha_{f}^{\varepsilon}\left(P_{h} / P_{f}\right)^{-\varepsilon}}{\left[\alpha_{h}^{\varepsilon}\left(P_{h} / P_{f}\right)^{1-\varepsilon}+\alpha_{f}^{\varepsilon}\right]^{2}}>0 .
\end{gathered}
$$

Given that $n_{i}$ is constant in the short run, changes in profit levels come 
only from changes in the relative expenditure share:

$$
\begin{aligned}
\frac{\partial \pi_{f}}{\partial\left(P_{h} / P_{f}\right)} & =\frac{\mu_{f}^{\prime}}{n_{f} \sigma} E>0, \\
\frac{\partial \pi_{h}}{\partial\left(P_{h} / P_{f}\right)} & =-\frac{\mu_{f}^{\prime}}{n_{h} \sigma} E<0 .
\end{aligned}
$$

Via expenditure shifting from domestic brands toward imported ones, a reduction in trade costs increases the profit levels of firms in group $f$, while reducing the profit levels of group- $h$ firms. In Figure 1 , this change is shown as the upward shift of the downward-sloping curve (i.e., from point $E$ to point $\left.I^{\prime}\right)$.

Proposition 2: In the short run, given that $n_{f}<n_{h}$, the change in each group-f firm's profit due to trade liberalization is larger (in absolute value) than the change in each group-h firm's profit:

$$
\left|\frac{\partial \pi_{f}}{\partial t}\right|>\left|\frac{\partial \pi_{h}}{\partial t}\right| .
$$

This result has important implications. From (11) and Proposition 1, the relative number of imported brands tends to be smaller, which can occur due to the trade costs. In such a case, the short-run impact of trade liberalization is a relative increase in profits for imported brands. 
In the long run, entrepreneurs begin to move from group $h$ to group $f$. These movements tend to reduce the profit of each group- $f$ firm. However, there is an additional effect of these movements: further reduction in the price index $P_{f}$. Since the variety of imported brands has been widened, it becomes more preferable for Home consumers to purchase imported brands. From (12) and (13), this increases the relative price levels of group $h$ and mitigates the negative effect of an increasing number of brands in group $f$. As the inter-group substitution $\varepsilon$ becomes bigger, this effect becomes larger.

Now let us consider the change in the long-run profit levels. From (9), one can obtain

$$
n_{h} \pi_{h}+n_{f} \pi_{f}=E .
$$

Then, the equalized long-run profit can be obtained as

$$
\tilde{\pi}_{h}=\tilde{\pi}_{f}=\frac{E}{N \sigma}
$$

This implies that the long-run profit levels are independent of the level of trade costs. In the long run, changes in the profit levels will be cancelled out by entrepreneurs' shifts from domestic brands to imported brands.

Proposition 3: In the long run, from each firm's viewpoint, the short-run effect of trade liberalization is cancelled out by entrepreneurs' switching from domestic brands toward imported brands. 
It is important to note that the gradual switching of entrepreneurs result in increased foreign brand penetration.

By combining Propositions 1 and 2, one can examine the impact of gradual trade liberalization. Suppose that trade costs decline from $t$ to $t^{\prime}$ first, then from $t^{\prime}$ to $t^{\prime \prime}$, and so on. As the share of imported brands increases due to trade liberalization (Proposition 1), the impact of trade liberalization itself becomes smaller (Proposition 2). This implies that, as trade is liberalized more, the incentive for entrepreneurs to provide imported brands becomes smaller.

Figure 2 summarizes the above results. With increasing trade liberalization, the downward sloping curve moves upwards. The short-run equilibrium moves from $E$ to $I^{\prime}$. Then, the entrepreneurs' switching occurs and the relative profit levels will be equalized again: the new long-run equilibrium is obtained at $E^{\prime}$. As the share of imported brands increases, the upward shift of the curve becomes smaller.

\section{Concluding Remarks}

In this study, by constructing a simple monopolistic competition trade model, I have examined how trade liberalization (i.e., a decline in trade costs) can affect domestic entrepreneurs' decisions and the degree of foreign brand pen- 
etration. It has been shown that, as trade costs becomes lower, more entrepreneurs choose to provide foreign brands. However, the impact of trade liberalization (in terms of changes in profit levels) becomes smaller as more entreprenuers switch to foreign brands.

The present analysis must be regarded as very tentative. Hopefully it provides a useful paradigm for considering how trade liberalization affects the degree of foreign brand penetration. The model could be enriched with the inclusion of both FDI and outsourcing aspects in order to analyze the organization of firms. ${ }^{8}$

\section{References}

[1] Dixit, Avinash K., and Joseph Stiglitz (1977) "Monopolistic Competition and Optimum Product Diversity," American Economic Review, Vol. 67, pp. $297-308$.

[2] Helpman, Elhanan (1990) Monopolistic Competition and Trade Theory, Special Papers in International Finance, No. 16, International Finance Section, Princeton University.

[3] Helpman, Elhanan (2006) "Trade, FDI, and the Organization of Firms," Journal of Economic Literature, Vol. 44, pp. 589-630.

\footnotetext{
${ }^{8}$ See Helpman (2006) for a survey of the relevant literature.
} 
[4] Helpman, Elhanan and Paul R. Krugman (1985) Market Structure and Foreign Trade, Cambridge, Mass.: MIT Press.

[5] Marjit, Sugata, Hamid Beladi, and Tarun Kabiraj (2007) "Brand Name Collaboration and Optimal Tariff," Economic Modelling, Vol. 24, pp. 636-647.

[6] Matsuyama, Kiminori (1995) "Complementarities and Cumulative Processes in Models of Monopolistic Competition," Journal of Economic Literature, Vol. 33, pp. 701-729.

[7] Ono, Yoshiyasu (1990) "Foreign Penetration and National Welfare under Oligopoly," Japan and the World Economy, Vol. 2, pp. 141-154.

[8] Porter, Michael E., Hirotaka Takeuchi, and Mariko Sakakibara (2000) Can Japan Compete? Cambridge, Mass.: Perseus Publishing.

[9] Richardson, Martin (1998) "Foreign Entry and Domestic Welfare," Review of World Economics, Vol. 134, pp. 250-262.

[10] Venables, Anthony J. (1987) "Trade and Trade Policy with Differentiated Products: A Chamberlinian-Ricardian Model," Economic Journal, Vol. 97, pp. 700-717. 


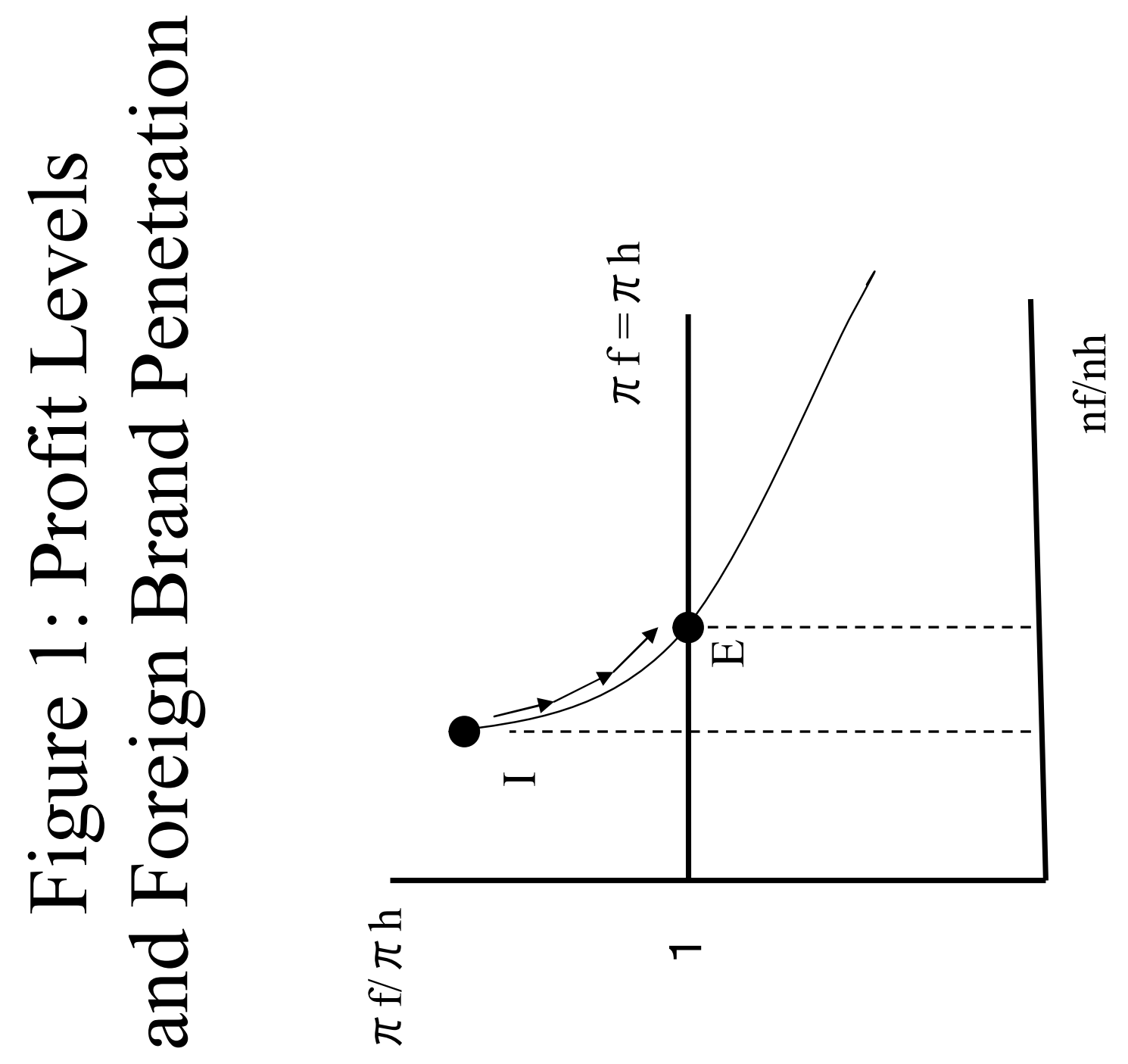



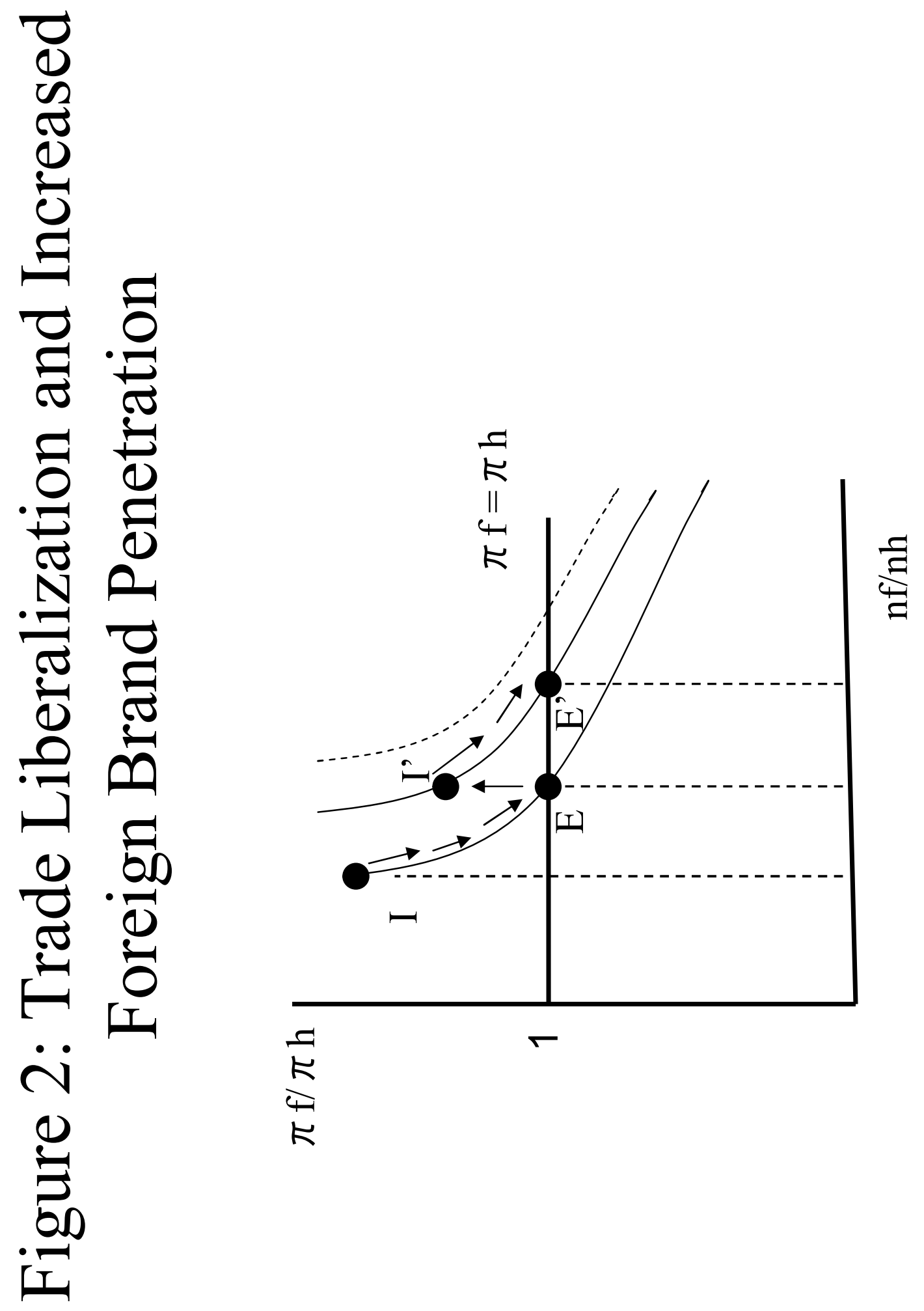